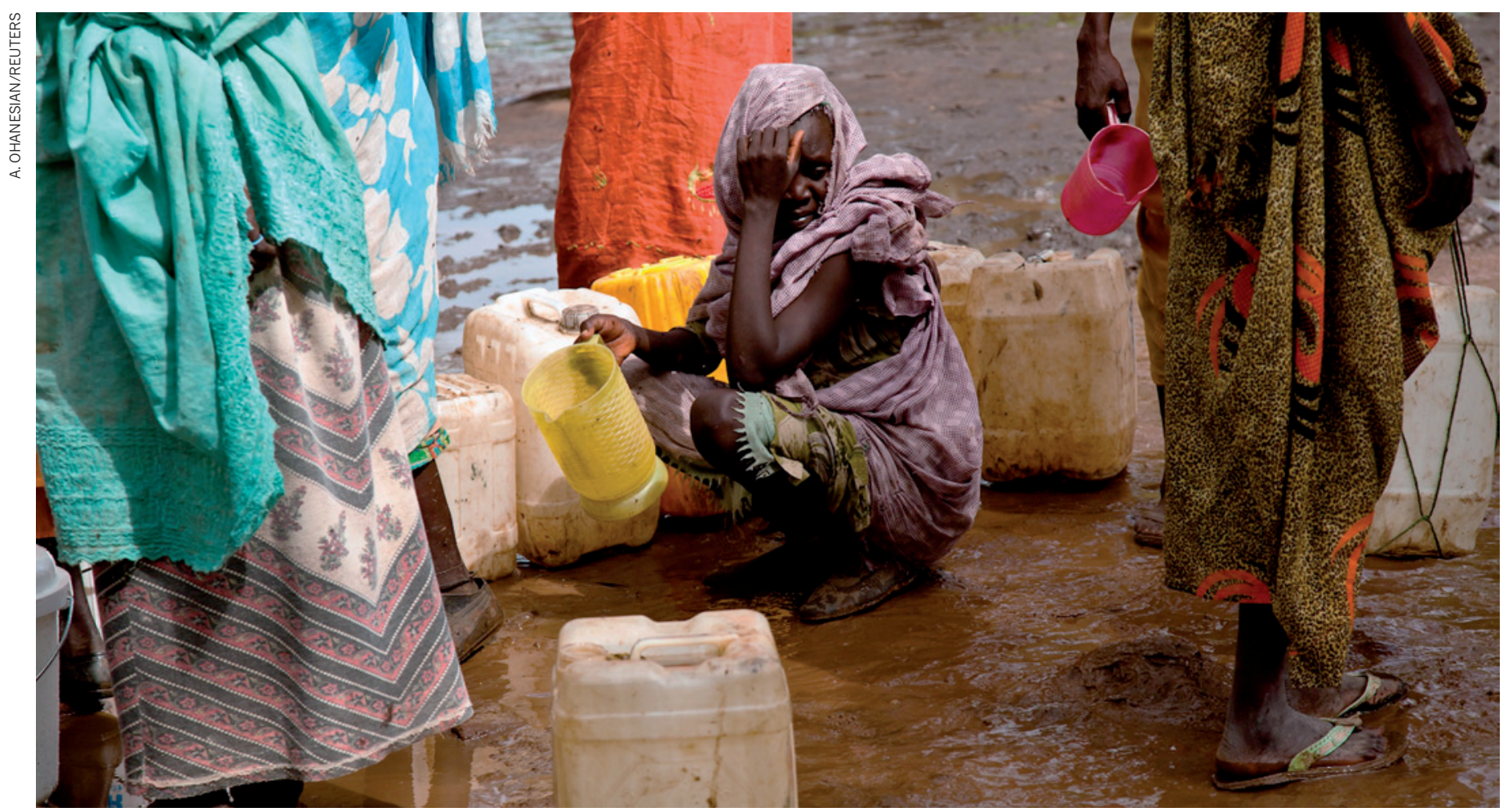

Poor sanitation at the Yusuf Batil refugee camp in South Sudan caused an outbreak of hepatitis E earlier this year.

\title{
IMMUNOLOGY
}

\section{Hepatitis E vaccine debuts}

\section{Success of Chinese biotech partnership raises hopes for prevention of overlooked diseases.}

\section{BY SOO BIN PARK}

$\mathrm{B}$ atches of the world's first vaccine against the hepatitis E virus began rolling out of a Chinese factory last week, promising to stem a disease that every year infects about 20 million people and claims 70,000 lives. The vaccine is being hailed as a victory for an unusual public-private partnership that could set a precedent in China's burgeoning biotechnology sector, and help to deliver other vaccines for diseases overlooked in the West.

The waterborne hepatitis E virus mostly occurs in developing countries that have poor sanitation, and it is particularly prevalent in east and south Asia. Although most cases cause only mild illness, it can lead to acute liver failure - the mortality rate reaches $4 \%$ in some regions and soars to $20 \%$ in women who are in the later stages of pregnancy. A severe outbreak of hepatitis E in the Xinjiang Uygur Autonomous Region in northwest China ${ }^{1}$, for example, caused almost 120,000 infections and more than 700 deaths between 1986 and 1988 (see 'Hidden epidemics'). There is no treatment, and improved sanitation has so far been the most effective way to stem the disease.

The new vaccine, which was approved by
China's State Food and Drug Administration (SFDA) in December 2011, could transform that picture. More than a decade ago, researchers at Xiamen University in Fujian province genetically modified a strain of the bacterium Escherichia coli to produce a protein that, when injected into humans, stimulates the body's immune system against hepatitis E. But preclinical and clinical development began in earnest only in 2000, when the Yangshengtang Group, a company with interests in food and health care, invested 15 million renminbi (US\$1.8 million in 2000) to set up a joint biotech laboratory in partnership with the university. The lab was given national status in 2006 by the Chinese Ministry of Science and Technology and relaunched as the National Institute of Diagnostics and Vaccine Development in Infectious Diseases (NIDVD).

The institute aims to unite academia and industry in commercializing new vaccines, particularly for emerging infectious diseases. Yangshengtang set up a subsidiary company called Innovax to take potential vaccines through clinical trials to manufacturing. The hepatitis E vaccine, Hecolin, is the company's first product to reach the market, but it also has a vaccine against human papilloma virus that is currently in preclinical research. Approval for Hecolin came after a phase III clinical trial published in 2010 showed that it was highly effective in preventing infection among almost 100,000 healthy participants ${ }^{2}$.

Hecolin cost about 500 million renminbi (US\$80 million) to develop, much of which came from the Chinese government through the university. The vaccine will be sold to distributors in China at a cost of 110 renminbi per dose, and the company expects it to reach sales of 62 million renminbi in 2013. That is hardly a blockbuster income, but, according to Jun Zhang, deputy director of the NIDVD, the public-private development model helps to ensure that vital vaccines are developed regardless of whether they prove to be profitable for manufacturers.

Zhang hopes that the success of Hecolin will attract further investment in such schemes, and says that the Chinese government has been encouraging. "Many people - including representatives of multinational pharmaceutical companies, venture capitalists, Chinese local government officials and Chinese entrepreneurs - think this is a worthy example of biotechnology investment," he says.

Zhang points out that UK drug-maker 


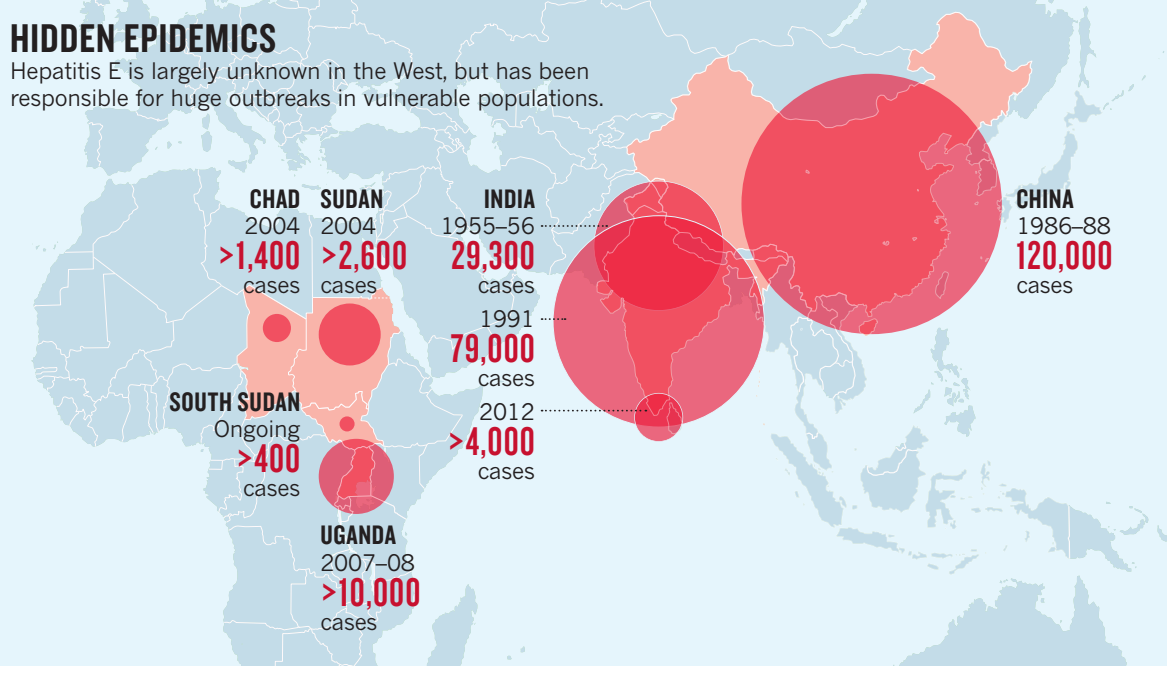

- GlaxoSmithKline had already developed a separate hepatitis E vaccine in collaboration with the US Army, which showed promise in phase II trials ${ }^{3}$. But with hepatitis E mostly occurring in developing countries, there was little commercial potential for the vaccine. "This is true not just of hepatitis E, but also many other plagues in the world," says Zhang.

Medical products for conditions such as hepatitis E that predominantly affect the developing world "are not seen as big money opportunities", agrees Jeremy Farrar, director of the Oxford University Clinical Research Unit in Ho Chi Minh City, Vietnam. "New companies operating with different funding models offer a great opportunity, and one which could have a profound impact."

Hecolin may have arrived just in time to tackle a rise in hepatitis E in Africa, where a 2007 outbreak ${ }^{4}$ in Uganda infected more than 10,000 people and killed 160. By the end of September this year, more than 200 cases of jaundice caused by hepatitis $\mathrm{E}$ had been reported in refugee camps in Kenya since August, and three refugee camps in South Sudan have seen 16 deaths and 400 cases of hepatitis E infection since July. "Cases are rising day by day, thus placing immense pressure on the available health services and resources. This is of grave humanitarian concern," said South Sudan's health ministry in a statement in September.

Xiamen University and Innovax are in talks with the World Health Organization (WHO) to register Hecolin with the organization's Prequalification Programme, which makes medicines available to agencies such as the United Nations Children's Fund and the Joint UN Programme on HIV/AIDS. "We have to be sure that these vaccines can be used anywhere," says Farrar. "It would be a great shame if these products were not available outside China."

"We have to accept that companies such as this one in China are going to be very important in the future," he adds. "The rest of us have to catch up. We need to find a way, through the $\mathrm{WHO}$, of ensuring the absolute transparency, safety and effectiveness of their vaccines." -

1. Zhuang, H., Cao, X. Y., Liu, C. B. \& Wang, G. M. Gastroenterol. Jpn. 26, 135-138 (1991).

2. Zhu, F.-C. et al. Lancet 376, 895-902 (2010).

3. Shrestha, M. P. et al. N. Engl. J. Med. 356, 895-903 (2007).

4. Teshale, E. H. et al. Emerg. Infect. Dis. 16, 126-129 (2010).

\section{Bid to curb fried-food chemical goes cold}

\section{Acrylamide levels still too high in Europe's food, says report.}

\section{BY KATHARINE SANDERSON}

$\mathrm{T}$ The rich, roasted aroma of coffee or the golden-brown colour of crispy French fries are enough to set most mouths watering. But the high-temperature cooking that gives these foods their alluring taste, scent and texture also adds a sting: acrylamide, a probable human carcinogen.

Swedish scientists discovered in 2002 that a wide range of baked and fried goods contain worryingly high levels of acrylamide ${ }^{1}-$ a simple organic molecule that is a neurotoxin and carcinogen in rats. The finding sparked an international effort to reduce concentrations of the chemical by changing ingredients and cooking methods.

Ten years on, a report ${ }^{2}$ from the European Food Safety Authority (EFSA) in Parma, Italy, suggests that this effort has stalled, amid patchy monitoring, uncertainty about acrylamide's true health effects and the challenge of weeding out a molecule present in hundreds of products.

Soon after the Swedish discovery, two teams - one led by chemist Donald Mottram at the University of Reading, UK, the other by Richard Stadler at Nestlé in Lausanne, Switzerland - unpicked the chemistry behind the problem ${ }^{3,4}$. They found that sugars and amino acids such as asparagine found in potatoes and cereals were making acrylamide $\left(\mathrm{C}_{3} \mathrm{H}_{5} \mathrm{NO}\right)$ as a by-product of the Maillard reaction, the very process that generates the heady blend of colour, flavour and taste in cooked foods.

Subsequent epidemiological studies involving tens of thousands of people have looked for links between acrylamide and various forms of cancer in humans, including breast ${ }^{5}$ and colorectal cancer ${ }^{6}$. For the most part, the results have been negative. In 2007, however, a Dutch study $^{7}$ of almost 2,600 women found that, among those who had never smoked, women consuming about 40 micrograms of acrylamide per day doubled their risk of developing cancers of the womb or ovaries, compared with those taking in roughly $10 \mu \mathrm{g}$ per day. And last month, a study ${ }^{8}$ showed that women who ate acrylamide-rich food during pregnancy tended to give birth to smaller babies.

Despite the uncertainties over the dangers of acrylamide, Europe's legislators and food producers vowed to take action. Since 2005, the industry group FoodDrinkEurope has maintained a 'toolbox' of tactics to help reduce acrylamide levels, such as changing potato varieties or storage conditions, and reducing cooking temperatures. According to Beate Kettlitz, the group's director of food policy, $90 \%$ of large and medium-sized companies in Europe now select potato varieties with low levels of the sugars that can form acrylamide, and all control French-fry cooking times to limit browning.

In 2007, the European Commission instructed the EFSA to collate yearly data on acrylamide levels. Last week, the authority released the most recent figures ${ }^{2}$ showing that acrylamide levels in finished food products hardly changed between 2007 and 2010. There have been isolated successes: in soft bread, for example, mean acrylamide levels dropped from 75 to $30 \mu \mathrm{g}$ per kilogram. But for crispbreads, 